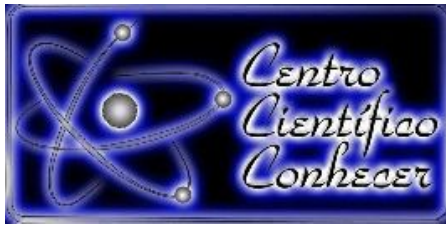

\title{
PRODUTIVIDADE DE BRACHIARIA HÍBRIDA CONVERT HD 364 SUBMETIDA A DIFERENTES DOSES DE NITROGÊNIO
}

Angélica Padilha de Freitas ${ }^{1}$, Leidinéia Cristiane Xavier Martins ${ }^{2}$, Priscila da Silva Salmazo $^{3}$, Marice Cristine Vendruscolo ${ }^{4}$

${ }^{1}$ Graduanda do Curso de Agronomia, Universidade do Estado de Mato Grosso

(UNEMAT), Tangará da Serra-MT, Brasil. E-mail: angelicafreitaas@hotmail.com

2, 3 Graduandas do Curso de Agronomia, Universidade do Estado de Mato Grosso

(UNEMAT), Tangará da Serra-MT, Brasil.

${ }^{4}$ Professora do curso de agronomia, Universidade do Estado de Mato Grosso (UNEMAT), Tangará da Serra-MT, Brasil.

Recebido em: 02/06/2019 - Aprovado em: 15/06/2019 - Publicado em: 22/07/2019

DOI: 10.18677/Agrarian_Academy_2019a28

\section{RESUMO}

Diante da necessidade de diversificação dos monocultivos de plantas forrageiras, novas cultivares estão sendo introduzidas no mercado. Objetivou-se, com este trabalho, avaliar as características da Brachiaria hibrida cv. Mulato II, conhecida como CONVERT HD 364, submetida a diferentes doses de adubação nitrogenada, utilizando a ureia como fonte de nitrogênio. O experimento foi conduzido em blocos casualizados, com seis tratamentos (doses de 0,50,100,150, 200 e $250 \mathrm{~kg} / \mathrm{ha}$ de N) e quatro repetições, em parcelas de $9 \mathrm{~m}^{2}$. As doses foram parceladas em quatro vezes, aplicadas após cada corte. Verificou-se que as maiores doses proporcionaram acréscimos sobre a altura de plantas, produção de massa verde, massa seca, massa seca de folhas e colmos. Ao mesmo tempo, houve decréscimos na porcentagem de massa seca do capim Convert. As doses de 200 e $250 \mathrm{~kg} / \mathrm{ha}$ de $\mathrm{N}$ são as mais recomendadas para o capim Convert.

PALAVRAS-CHAVE: Adubação nitrogenada, Pastagem, Produtividade.

\section{PRODUCTION OF BRACHIARIA HYBRID CONVERT HD 364 SUBMITTED TO DIFFERENT DOSES OF NITROGEN}

\section{ABSTRACT}

Faced with the need for diversification of forage plants monocultures, new cultivars are being introduced in the market. The objective of this work was to evaluate the characteristics of Brachiaria hibrida cv. Mulato II, known as CONVERT HD 364, submitted to different doses of nitrogen fertilization, using 9 urea as source of nitrogen. The experiment was conducted in a randomized complete block with six treatments (doses of $0,50,100,150,200$ and $250 \mathrm{~kg} / \mathrm{ha}$ of $\mathrm{N}$ ) and four replications, in $9 \mathrm{~m}^{2}$ plots. The doses were divided in four times, applied after each cut. It was AGRARIAN ACADEMY, Centro Científico Conhecer - Goiânia, v.6, n.11; p. 292 
verified that the higher fertilization doses provided increases on height of plants, production of green mass, dry mass, dry mass of leaves and stems. At the same time, there were decreases in the percentage of dry mass of the Convert grass. The doses of 200 and $250 \mathrm{~kg} / \mathrm{ha}$ of $\mathrm{N}$ are the most recommended for the Convert grass. KEYWORDS: Nitrogen fertilization, Pasture, Productivity.

\section{INTRODUÇÃO}

A atividade pecuária é dividida em dois segmentos, a pecuária de corte e a de leite. Segundo dados do IBGE (2017), o Brasil dispõe do maior rebanho comercial do mundo, com 218,2 milhões de cabeças, dos quais 19,67 milhões contribuem para a pecuária leiteira, com produção de 33,62 bilhões de litros de leite.

O Brasil é o maior exportador de carne bovina do mundo; em 2016, abateu 36,9 milhões de animais, produzindo 9,14 milhões de toneladas de carne; destes, foram destinados para exportação $19,97 \%$ e a carne in natura representou $76,5 \%$ dos produtos exportados, sendo os principais compradores Hong Kong, Egito, China e Rússia (ABIEC, 2017). As pastagens são formadas por plantas chamadas de forrageiras, que constituem a base alimentar para bovinos, tanto de corte quanto de leite, representando o recurso mais prático e econômico de oferta de alimento (OLIVEIRA et al., 2015).

No Brasil, os capins do gênero Brachiaria (Syn. Urochloa) são os mais cultivados, por apresentarem alta produtividade, bom teor nutricional e persistência no pasto ao longo dos anos. O capim Marandu, popularmente conhecido como Braquiarão, abrange grande parte das pastagens no Estado de Mato Grosso (PEDREIRA et al., 2014).

Diante disso, novas forrageiras estão sendo lançadas no mercado, através de técnicas de melhoramento genético para diversificação dos monocultivos, que buscam, além do aumento de produtividade e qualidade dos pastos, adaptação a diferentes tipos de clima, solo, manejo e resistência ao ataque de pragas e doenças, como é o caso da Brachiaria hibrida Convert HD 364, que reúne características de três espécies (Brachiaria decumbens, Brachiaria ruziziensis e Brachiaria brizantha) nesta forrageira (FIORI, 2016).

O potencial produtivo de cada planta é definido geneticamente, no entanto, a disponibilidade de nutrientes e o manejo adequado são fundamentais para que esse potencial seja alcançado (CARDOSO et al., 2015). Sendo assim, o fornecimento de nutrientes, em quantidades adequadas, é determinante para a produtividade das pastagens. Entre estes, a disponibilidade 11 de nitrogênio merece destaque na produção e qualidade das pastagens (SALES et al., 2014).

O nitrogênio é o nutriente exigido em maiores quantidades e o segundo fator mais limitante para o desenvolvimento das forrageiras, sendo o primeiro fator, a disponibilidade hídrica. Nas pastagens, a fonte de nitrogênio comumente empregada é a ureia aplicada em superfície, que contém alta concentração de nitrogênio (44 a $46 \%$ ) e é de fácil manipulação (HOFFMANN et al., 2014).

O nitrogênio é essencial para o crescimento e desenvolvimento da planta, atua positivamente no número, tamanho, peso de folhas e perfilhos, que são fatores importantes na produção de massa seca e valor nutritivo da planta, assim como aumenta o vigor de rebrota (TEIXEIRA et al., 2015).

Objetivou-se, com este trabalho, avaliar as características da Brachiaria hibrida cV. Mulato II, conhecida como CONVERT HD 364, submetida a diferentes doses de adubação nitrogenada, utilizando a ureia como fonte de nitrogênio. 


\section{MATERIAL E MÉTODOS}

O experimento foi conduzido na área experimental da Universidade do Estado de Mato Grosso - UNEMAT, Câmpus Universitário Professor Eugênio Carlos Stieler, localizado às margens da Rodovia MT - 358, $\mathrm{km} \mathrm{7,} \mathrm{Jardim} \mathrm{Aeroporto,} \mathrm{no} \mathrm{município}$ de Tangará da Serra - MT. O clima da região apresenta precipitação média anual de $1.815,5 \mathrm{~mm}$ e temperatura média por volta de $26,1^{\circ} \mathrm{C}$ (DALLACORT et al., 2010).

$O$ delineamento experimental utilizado foi 0 delineamento em blocos casualizados (DBC). Os tratamentos consistiram de seis doses crescentes de nitrogênio $(0,50,100,150,200,250 \mathrm{~kg} / \mathrm{ha})$, com quatro repetições. As parcelas mediram $3 \mathrm{~m} \times 3 \mathrm{~m}\left(9 \mathrm{~m}^{2}\right)$ e, no momento das avaliações foram desprezados 12 0,5 $\mathrm{m}$ de cada lado, devido ao efeito de bordadura, totalizando uma área útil de $4 \mathrm{~m}^{2}$. $\mathrm{O}$ preparo do solo foi realizado inicialmente com uma roçagem, rebaixando a cultura anteriormente instalada, a Brachiaria brizantha cv. Marandu, que se encontrava em pousio e, posteriormente foram feitas duas gradagens na área.

Foram retiradas subamostras na profundidade de $0-20 \mathrm{~cm}$, para constituir a amostra de solo encaminhada ao laboratório para verificação dos atributos químicos e físicos. Os resultados da análise estão apresentados na Tabela 1. Com base nos resultados obtidos na análise, realizou-se a calagem, no dia 08 de dezembro de 2017, com calcário calcítico de PRNT $80 \%$ em área total, de $80 \mathrm{~m} \times 30 \mathrm{~m}$, com auxílio de calcareadora, incorporado ao solo mediante outras duas gradagens. As adubações fosfatada e potássica foram realizadas no momento da semeadura, a lanço, na quantidade de $1.000 \mathrm{~kg} / \mathrm{ha}$ de superfosfato simples e $68,95 \mathrm{~kg} / \mathrm{ha}$ de cloreto de potássio, incorporadas manualmente ao solo com auxílio de enxada.

A semeadura da Brachiaria hibrida cv. Mulato II, popularmente conhecida como Convert HD364 ocorreu em 19 de dezembro de 2017, utilizando-se $15 \mathrm{~kg}$ de sementes incrustradas por hectare, com $92 \%$ de pureza e $67 \%$ de germinação.

As adubações nitrogenadas foram realizadas a lanço, parceladas em quatro aplicações, utilizando como fonte de nitrogênio a ureia. A primeira aplicação foi efetuada em 03/02/2018, quando as plantas estavam com $25 \mathrm{~cm}$ de altura, aproximadamente. As três aplicações restantes foram realizadas a cada 28 dias, após a retirada das amostras e a uniformização do pasto a $25 \mathrm{~cm}$ do solo, feito com roçadora costal, em todas as parcelas. Após o corte de uniformização, o material vegetal era retirado das parcelas com o auxílio de um rastelo.

As variáveis analisadas no experimento foram altura de planta, produção de massa verde e seca por hectare, número de perfilhos por $\mathrm{m}^{2}$, número de folhas por perfilho, peso seco por perfilho, relação folha: colmo, produção por hectare de folhas, colmos e material senescente. A mensuração da altura das plantas foi realizada de forma aleatória, em 10 plantas de cada parcela, com o auxílio de uma fita métrica, antes da coleta das amostras. A altura foi considerada da lâmina mais alta do dossel, a partir do nível do solo.

Para determinação da massa verde foram realizados quatro cortes a cada 28 dias, sendo estes no dia 07/03, 04/04, 01/05 e 31/05/2018. Para isso, utilizou-se um quadrado de cano PVC, nas dimensões de $0,5 \mathrm{~m} \times 0,5 \mathrm{~m}$, com altura de $25 \mathrm{~cm}$, que foi colocado de forma aleatória dentro da área útil das parcelas e as plantas que encontravam-se no quadrado, eram cortadas com o auxílio de uma tesoura de poda. Todas as amostras coletadas foram acondicionadas em sacos plásticos identificados de acordo com cada dose, transportados ao laboratório e pesados.

De cada amostra do quadrado de $0,5 \mathrm{~m} \times 0,5 \mathrm{~m}$, foi retirada uma subamostra de aproximadamente $200 \mathrm{~g}$ e a partir dessa subamostra foram separados, no laboratório, com auxílio de uma tesoura, o colmo das folhas, sendo que também 
foram separados na subamostra material senescente, para determinação da massa verde e massa seca por hectare.

Foi contado o número de perfilhos contidos no quadrado de $0,5 \mathrm{~m} \times 0,50 \mathrm{~m}$ para a determinação do número de perfilhos por $\mathrm{m}^{2}$. Foram coletados 20 perfilhos, rente ao solo, de forma aleatória, com o auxílio de uma tesoura, em cada parcela. $\mathrm{Na}$ amostra coletada a campo dos 20 perfilhos, foi contado o número de folhas, a fim de verificar o número de folhas por perfilho e para a determinação da massa seca por perfilho.

Após serem devidamente separadas todas as amostras, foram pesadas e colocadas em sacos de papel identificados individualmente, na estufa com circulação de ar forçada, a 55C por 72 horas; após esse período foram retiradas da estufa e pesadas novamente para determinação da massa seca. Os dados coletados foram submetidos a análise de variância pelo teste $F$ e quando apresentaram significância foi realizada a análise de regressão, utilizando-se o programa estatístico ASSISTAT.

\section{RESULTADOS E DISCUSSÃO}

A altura de plantas não diferiu significativamente entre as doses de nitrogênio apenas no primeiro corte, apresentando altura média de 0,84 m (Tabela 2).

TABELA 2. Média da altura de plantas ( $A L)$, número de perfilhos por $m^{2}(N P)$, porcentagem de massa seca (\%MS), massa seca de perfilhos (MSP), número de folhas por perfilho (NFP) e relação folha: colmo (FC) do capim Convert sob diferentes doses de nitrogênio em Tangará da Serra - MT.

\begin{tabular}{|c|c|c|c|c|c|c|}
\hline & $\overline{\mathrm{AL}(\mathrm{m})}$ & $\mathrm{NP}\left(\mathrm{m}^{2}\right)$ & $\% \mathrm{MS}$ & MSP (g) & NFP & $\mathrm{FC}$ \\
\hline \multicolumn{7}{|c|}{ Corte } \\
\hline 10 & $0,84^{\mathrm{ns}}$ & $191,33^{\text {ns }}$ & $26,99^{\text {ns }}$ & $1,53^{\text {ns }}$ & $3,92^{\text {ns }}$ & $3,92^{\mathrm{ns}}$ \\
\hline $2^{\circ}$ & $0,61^{*}$ & $163,17^{\mathrm{ns}}$ & $19,63^{\text {ns }}$ & $1,01^{\mathrm{ns}}$ & $4,04^{\mathrm{ns}}$ & $8,35^{\mathrm{ns}}$ \\
\hline $3^{0}$ & $0,62^{* *}$ & $245,00^{\mathrm{ns}}$ & $23,91^{*}$ & $0,72^{\text {ns }}$ & $3,24^{\mathrm{ns}}$ & $10,73^{\text {ns }}$ \\
\hline $4^{\circ}$ & $0,46^{* *}$ & $233,33^{\mathrm{ns}}$ & $23,63^{\mathrm{ns}}$ & $0,99^{\text {ns }}$ & $4,07^{\text {ns }}$ & $8,36^{\mathrm{ns}}$ \\
\hline
\end{tabular}

${ }^{\text {ns }}$ não significativo; * significativo a $5 \% ;{ }^{\star *}$ significativo a $1 \%$.

O segundo corte demonstrou diferença significativa $(P \leq 0,01)$, sendo verificada a maior altura, de $0,64 \mathrm{~m}$ para a dose de $200 \mathrm{~kg} / \mathrm{ha}$ de $\mathrm{N}$ (Figura 1). Corroborando com esses resultados, Carard et al. (2008), aplicando $200 \mathrm{~kg} / \mathrm{ha}$ de N, encontraram crescimento máximo na Brachiaria brizantha cv. MG4, enquanto que a Brachiaria brizantha cv. Marandu, obteve maiores alturas com a utilização de 100 $\mathrm{kg} / \mathrm{ha}$ de $\mathrm{N}$.

Nos demais cortes houve diferença significativa $(P \leq 0,05)$ entre os tratamentos. No terceiro corte a altura das plantas atingiu até $0,70 \mathrm{~m}$ com a quantidade de $250 \mathrm{~kg} / \mathrm{ha}$ de $\mathrm{N}$ (Figura 1). Este resultado foi superior ao encontrado por Silva Filho et al. (2014) que, mensurando a altura da cultivar Marandu obteve $0,64 \mathrm{~m}$ para a dose de $250 \mathrm{~kg} / \mathrm{ha}$ de $\mathrm{N}$. No quarto corte a altura máxima, de $0,50 \mathrm{~m}$ ocorreu nas doses de 100 e $250 \mathrm{~kg} / \mathrm{ha}$ de $\mathrm{N}$ (Figura 1). 

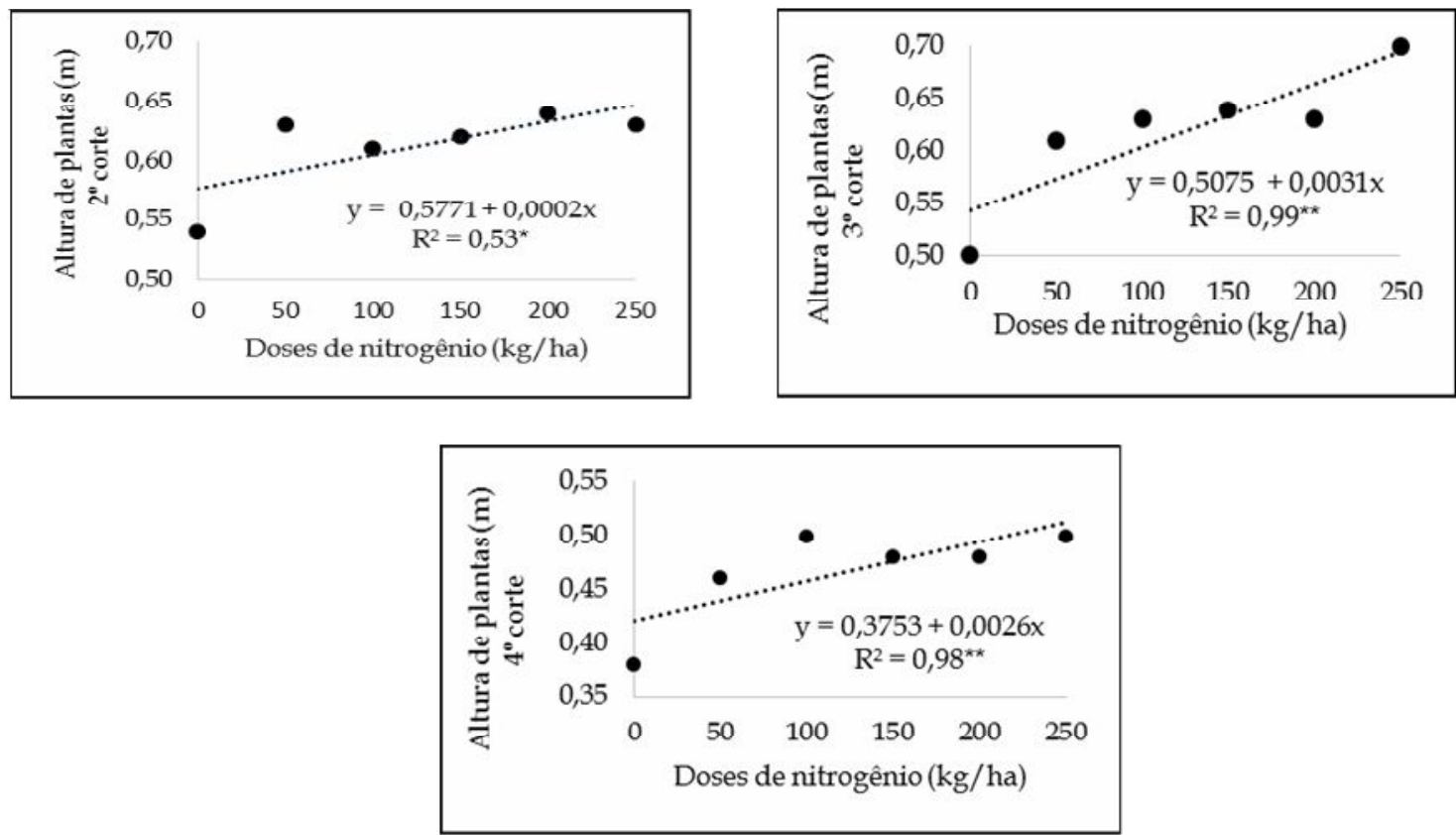

FIGURA 1. Altura de plantas no segunto, terceiro e quarto cortes do capim Convert sob diferentes doses de nitrogênio em Tangará da Serra - MT.

Em relação à porcentagem de massa seca, no primeiro, segundo e quarto cortes não houveram diferenças significativas entre as doses utilizadas (Tabela 2), somente houve efeito significativo $(P \leq 0,01)$ no terceiro corte (Figura 2). Resultados semelhantes foram verificados por Cardoso et al. (2015), nos quais houve redução dos teores de massa seca, à medida em que aumentavam as doses de nitrogênio, nas cultivares Marandu e Convert, respectivamente.

Observou-se entre as variáveis apresentadas na Tabela 2, que para o número de perfilhos por $\mathrm{m}^{2}$, massa seca de perfilhos, número de folhas por perfilho e a relação folha: colmo, não houveram diferenças significativas entre as doses de nitrogênio utilizadas durante a condução do experimento.

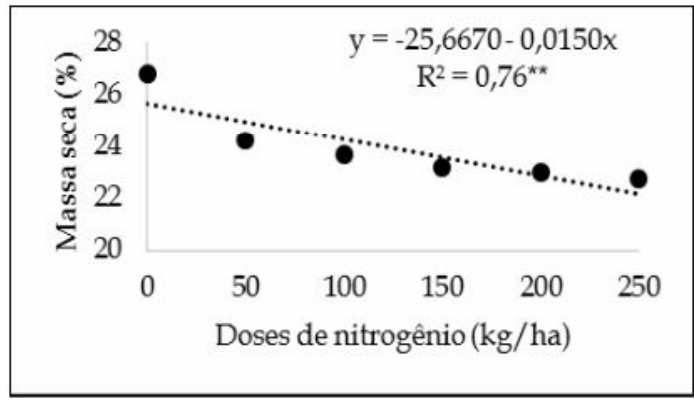

FIGURA 2. Porcentagem de massa seca no terceiro corte do capim Convert sob diferentes doses de nitrogênio em Tangará da Serra - MT.

A produtividade da planta forrageira é resultado da constante emissão de folhas e perfilhos, necessária para a reconstituição da área foliar após o corte ou pastejo, que garante a longevidade do pasto (BASSO et al., 2010). Apesar da relação folha: colmo não ter sido influenciada pelas doses de nitrogênio utilizadas, apresentou valores superiores ao considerado crítico (1:1) e quanto maior for essa 
relação, maior será o valor nutritivo aos animais, visto que as folhas são preferencialmente mais consumidas e nutritivas que os colmos (BRITO et al., 2015).

Segundo Jacovetti (2016), plantas forrageiras tropicais podem atingir até o máximo de sete folhas por perfilho, resultados que corroborram com os deste trabalho. Cabral (2011) relata que independente da dose utilizada de nitrogênio, na cultivar Convert houve predominância de folhas, que é fator importante para a produção animal a pasto.

$\mathrm{Na}$ Tabela 3 estão descritos os dados de massa verde, massa seca, massa seca de folhas, massa seca de colmos e massa seca de material senescente. Somente apresentaram diferença significativa entre as doses de nitrogênio no terceiro corte, as variáveis massa seca e massa seca de colmos $(P \leq 0,01)$ e massa verde e massa seca de folhas $(P \leq 0,05)$.

TABELA 3. Média da massa verde (MV), massa seca (MS), massa seca de folhas (FL), massa seca de colmos (CO) e massa seca de material senescente (MSE) do capim Convert sob diferentes doses de nitrogênio em Tangará da Serra - MT.

\begin{tabular}{|c|c|c|c|c|c|}
\hline & $\begin{array}{c}\text { MV } \\
(\mathrm{kg} / \mathrm{ha})\end{array}$ & $\begin{array}{c}\mathrm{MS} \\
(\mathrm{kg} / \mathrm{ha})\end{array}$ & $\begin{array}{c}\mathrm{FL} \\
(\mathrm{kg} / \mathrm{ha})\end{array}$ & $\begin{array}{l}\text { CO } \\
\text { (kg/ha) }\end{array}$ & $\begin{array}{l}\text { MSE } \\
(\mathrm{kg} / \mathrm{ha})\end{array}$ \\
\hline \multicolumn{6}{|c|}{ Corte } \\
\hline 10 & $13115,16^{\mathrm{ns}}$ & $3502,12^{\mathrm{ns}}$ & $2671,10^{\text {ns }}$ & $810,02^{n s}$ & $0,00^{\mathrm{ns}}$ \\
\hline 20 & $7561,83^{\text {ns }}$ & $1488,46^{\text {ns }}$ & $1237,91^{\mathrm{ns}}$ & $214,95^{\text {ns }}$ & $18,24^{\mathrm{ns}}$ \\
\hline $3^{\circ}$ & $8382,16^{\star *}$ & $1979,24^{*}$ & $1729,05^{\star *}$ & $196,13^{*}$ & $24,13^{\mathrm{ns}}$ \\
\hline $4^{\circ}$ & $7265,50^{\text {ns }}$ & $1716,47^{\mathrm{ns}}$ & $1438,77^{\text {ns }}$ & $206,27^{\mathrm{ns}}$ & $63,14^{\mathrm{ns}}$ \\
\hline
\end{tabular}

${ }^{\text {ns }}$ não significativo; * significativo a 5\%; ** significativo a $1 \%$.

A maior produção de massa verde da forragem, $10.132 \mathrm{~kg} / \mathrm{ha}$ foi obtida em resposta à adubação com 200 kg/ha de N (Figura 3).

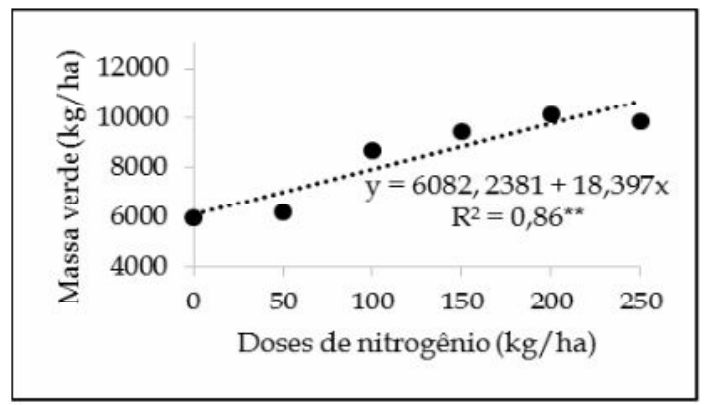

FIGURA 3. Massa verde no terceiro corte do capim Convert sob diferentes doses de nitrogênio em Tangará da Serra - MT.

Resultados inferiores são relatados por Augusto et al. (2018), durante a realização do terceiro corte, na quantidade de $200 \mathrm{~kg} / \mathrm{ha}$, que identificaram produção de $4.848 \mathrm{~kg} / \mathrm{ha}$ de massa verde no Panicum maximum cv. Mombaça irrigado. De acordo com Emerenciano Neto et al. (2016), o aumento das doses de nitrogênio (0 a $150 \mathrm{~kg} / \mathrm{ha}$ ) contribuiu para maiores produções de massa verde no capim Convert.

Teodoro (2007), trabalhando com diferentes doses de nitrogênio (0, 100, 200 e $300 \mathrm{~kg} / \mathrm{ha}$ ), nas cultivares Brachiaria hibrida cv. Mulato I e Brachiaria brizantha cv. Marandu constatou que altas doses, de $300 \mathrm{~kg} / \mathrm{ha}$ de $\mathrm{N}$, não proporcionaram maior produção de massa verde, pelo contrário, apresentaram resultados inferiores à dose de $100 \mathrm{~kg} / \mathrm{ha}$ de $\mathrm{N}$ e que nas condições do experimento o limite de resposta das 
forrageiras, estava em torno de $200 \mathrm{~kg} / \mathrm{ha}$. Em relação à massa seca da planta inteira, a dose de $200 \mathrm{~kg} / \mathrm{ha}$ de nitrogênio apresentou o máximo de $2.303 \mathrm{~kg} / \mathrm{ha}$ (Figura 4).

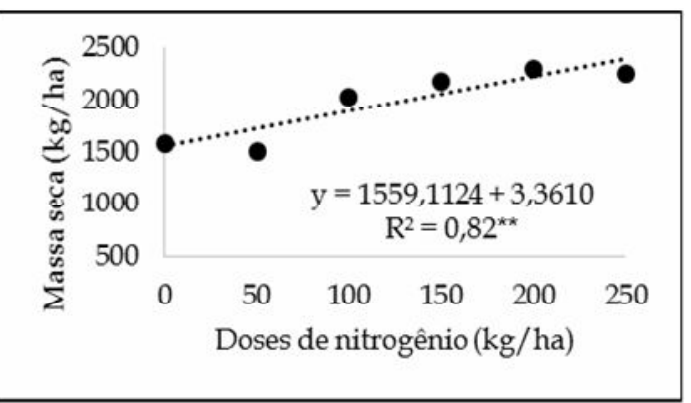

FIGURA 4. Massa seca no terceiro corte do capim Convert sob diferentes doses de nitrogênio em Tangará da Serra - MT.

Resultado superior ao observado por Freitas et al. (2005), em pastagem de capim Mombaça, que obteve produção de massa seca de $2.216 \mathrm{~kg} / \mathrm{ha}$ para a dose de $210 \mathrm{~kg} / \mathrm{ha}$. Leal (2014), avaliando o capim Convert, relata que houve descréscimo nos valores de massa seca a partir da adubação com $150 \mathrm{~kg} / \mathrm{ha}$ de N. Quanto à massa seca de folhas, a adubação com $200 \mathrm{~kg} / \mathrm{ha}$ proporcionou melhores resultados (Figura 5).

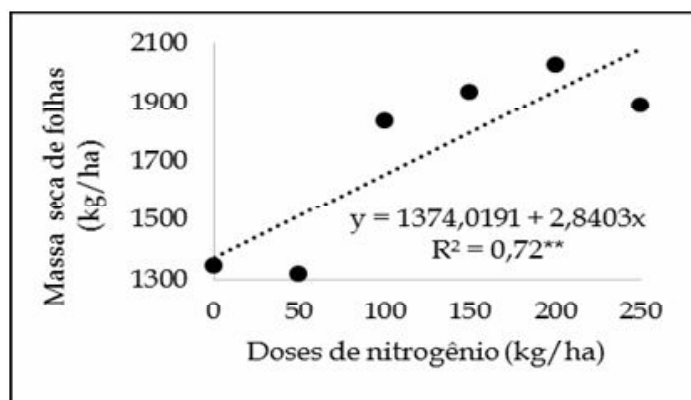

FIGURA 5. Massa seca de folhas no terceiro corte do capim Convert sob diferentes doses de nitrogênio em Tangará da Serra - MT.

Porto (2017), estudando três cultivares de Brachiaria brizantha, verificou que o potencial de respostas da adubaçâo nitrogenada foi diferente para cada forrageira, em que o capim Piatã e o Marandu obtiveram resultados superiores com a dose de $160 \mathrm{~kg} / \mathrm{ha}$, já o capim Xaráes apresentou maiores rendimentos de massa seca de folhas com a maior dose, de $240 \mathrm{~kg} / \mathrm{ha}$ de $\mathrm{N}$. A massa seca de colmos apresentou os maiores valores para a adubação com $250 \mathrm{~kg} /$ ha de N (Figura 6).

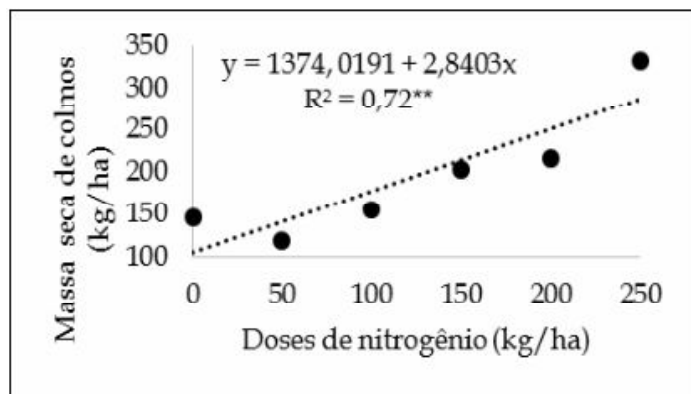

FIGURA 6. Massa seca de colmos no terceiro corte do capim Convert sob diferentes doses de nitrogênio em Tangará da Serra - MT. 
Como verificado por Dourado (2009), utilizando doses de até $500 \mathrm{~kg} / \mathrm{ha}$ de N na cultivar Piatã, a capacidadade máxima de resposta da cultivar seria atingida fora do intervalo de estudo com aumento das doses de N. A massa seca de material senescente não apresentou diferença significativa entre os tratamentos (Tabela 3).

TABELA 3. Média da massa verde (MV), massa seca (MS), massa seca de folhas $(\mathrm{FL})$, massa seca de colmos (CO) e massa seca de material senescente (MSE) do capim Convert sob diferentes doses de nitrogênio em Tangará da Serra - MT.

\begin{tabular}{|c|c|c|c|c|c|}
\hline & $\begin{array}{c}\mathrm{MV} \\
(\mathrm{kg} / \mathrm{ha})\end{array}$ & $\begin{array}{c}\mathrm{MS} \\
(\mathrm{kg} / \mathrm{ha})\end{array}$ & $\begin{array}{c}\mathrm{FL} \\
(\mathrm{kg} / \mathrm{ha})\end{array}$ & $\begin{array}{l}\mathrm{CO} \\
(\mathrm{kg} / \mathrm{ha})\end{array}$ & $\begin{array}{l}\text { MSE } \\
(\mathrm{kg} / \mathrm{ha})\end{array}$ \\
\hline \multicolumn{6}{|c|}{ Corte } \\
\hline $1^{0}$ & $13115,16^{\mathrm{ns}}$ & $3502,12^{\text {ns }}$ & $2671,10^{\text {ns }}$ & $810,02^{\text {ns }}$ & $0,00^{\mathrm{ns}}$ \\
\hline $2^{\circ}$ & $7561,83^{\mathrm{ns}}$ & $1488,46^{\text {ns }}$ & $1237,91^{\mathrm{ns}}$ & $214,95^{\mathrm{ns}}$ & $18,24^{\mathrm{ns}}$ \\
\hline $3^{\circ}$ & $8382,16^{\star *}$ & $1979,24^{*}$ & $1729,05^{\star *}$ & $196,13^{*}$ & $24,13^{\mathrm{ns}}$ \\
\hline $4^{\circ}$ & $7265,50^{\mathrm{ns}}$ & $1716,47^{\mathrm{ns}}$ & $1438,77^{\mathrm{ns}}$ & $206,27^{\text {ns }}$ & $63,14^{\mathrm{ns}}$ \\
\hline
\end{tabular}

${ }^{\text {ns }}$ não significativo; * significativo a 5\%; ${ }^{* *}$ significativo a $1 \%$.

Segundo Iwamoto et al. (2015), no verão os processos de formação dos tecidos são acelerados e acabam reduzindo a duração da vida das folhas e consequentemente elevam a taxa de senescência foliar. Na Tabela 4 estão descritas as somas dos quatro cortes e a média dos quatro cortes, das variáveis analisadas, de acordo as respectivas doses de nitrogênio. Somente a altura de plantas apresentou diferença significativa a $1 \%$ de probabilidade.

TABELA 4. Média da altura de plantas dos quatro cortes ( $A L)$, do número de perfilhos por $\mathrm{m}^{2}$ (NP), da porcentagem de massa seca (\%MS), da massa seca por perfilho (MSP), do número de folhas por perfilho (NFP), da relação folha: colmo (FC), massa verde total dos quatro cortes (MVT), massa seca total dos quatro cortes (MST), massa seca total de folhas dos quatro cortes (FLT), massa seca total de colmos dos quatro cortes (COT) e massa seca total de material senescente dos quatro cortes (MSET) do capim Convert sob diferentes doses de nitrogênio em Tangará da Serra - MT.

\begin{tabular}{|c|c|c|c|c|c|c|c|}
\hline Dose $\mathrm{kg} / \mathrm{ha}$ & 0 & 50 & 100 & 150 & 200 & 250 & CV (\%) \\
\hline $\mathrm{AL}(\mathrm{m})^{\star *}$ & 0,55 & 0,64 & 0,65 & 0,65 & 0,65 & 0,67 & 3,85 \\
\hline$N P\left(m^{2}\right)^{n s}$ & 195 & 171,25 & 172,5 & 223 & 242 & 245,5 & 21,66 \\
\hline$\% \mathrm{MS}^{\mathrm{ns}}$ & 24,81 & 23,92 & 23,59 & 23,06 & 22,73 & 23,14 & 4,19 \\
\hline $\operatorname{MSP}(g)^{n s}$ & 0,94 & 1,08 & 0,99 & 1,09 & 1,2 & 1,06 & 13,96 \\
\hline$N F P^{n s}$ & 3,81 & 3,69 & 3,59 & 3,9 & 4,14 & 3,82 & 6,79 \\
\hline $\mathrm{FC}^{\text {ns }}$ & 7,79 & 10,11 & 8,05 & 7,42 & 7,43 & 6,25 & 31,52 \\
\hline MVT $(\mathrm{kg} / \mathrm{ha})^{\mathrm{ns}}$ & 28501 & 30866 & 38142 & 37040 & 40765 & 42634 & 18,47 \\
\hline MST $(\mathrm{kg} / \mathrm{ha})^{\mathrm{ns}}$ & 7183 & 7573 & 9267 & 8587 & 9436 & 10071 & 18,95 \\
\hline $\operatorname{FLT}(\mathrm{kg} / \mathrm{ha})^{\mathrm{ns}}$ & 5889 & 6297 & 7253 & 7199 & 7855 & 7967 & 15,67 \\
\hline $\operatorname{COT}(\mathrm{kg} / \mathrm{ha})^{\mathrm{ns}}$ & 1089 & 1080 & 1838 & 1237 & 1432 & 1887 & 43,06 \\
\hline $\operatorname{MSET}(\mathrm{kg} / \mathrm{ha})^{\mathrm{ns}}$ & 119 & 94 & 119 & 63 & 119 & 119 & 47,27 \\
\hline
\end{tabular}

${ }^{n s}$ não signigicativo, ${ }^{* *}$ Interação significativa a $1 \%$

Observou-se que a altura das plantas expressou efeito positivo com as crescentes doses de nitrogênio utilizadas, sendo que na dose de $250 \mathrm{~kg} / \mathrm{ha}$ verificaram-se plantas mais altas, com 0,67 m (Figura 7). 


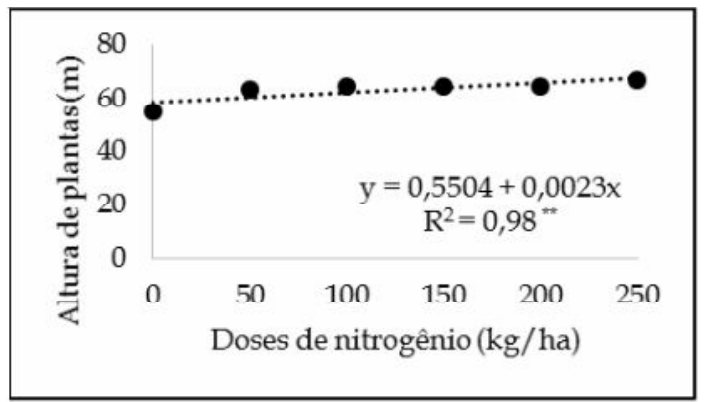

FIGURA 7. Altura média de plantas dos quatro cortes do capim Convert sob diferentes doses de nitrogênio em Tangará da Serra - MT.

Cardoso et al. (2015), avaliando a produtividade do capim Marandu, utilizando como fonte de nitrogênio, uréia e sulfato de amônio, concluíram que as maiores alturas de plantas foram respectivamente 113,08 e 90,36 cm, alcançadas com a maior dose utilizada de $510 \mathrm{~kg}$ de $\mathrm{N}$, porém, a adubação com uréia proporcionou altura superior, quando comparada ao sulfato de amônio.

\section{CONCLUSÃO}

As maiores doses de nitrogênio, de 200 e $250 \mathrm{~kg} / \mathrm{ha}$, proporcionam acréscimos sobre as variáveis altura de plantas, massa verde, massa seca, massa seca de folhas e colmos do capim Convert, ao mesmo tempo em que há decréscimos na porcentagem de massa seca. As doses de 200 e $250 \mathrm{~kg} / \mathrm{ha}$ de $\mathrm{N}$ são as mais recomendadas para o capim Convert.

\section{REFERÊNCIAS}

ABIEC - Associação Brasileira das Indústrias Exportadoras de carne. Perfil da pecuária no Brasil: relatório anual. 2017. Disponível em: http://gtps.org.br/wpcontent/uploads/2017/08/Sumario_2017_screen.pdf

Acesso em: 28 abr. 2018.

BASSO, K.C.; CECATO, U.; LUGÃO, S.M.B.; GOMES, J.A.N.; BARBERO, L.M.; MOURÃO, G.B. Morfogênese e dinâmica do perfilhamento em pastos de Panicum maximum cv. Milênio submetido a doses de nitrogênio. Revista Brasileira de Saúde e Produção Animal, v.11, n.4, p.976-989, 2010.

BRITO, R. R.; GRASSI FILHO, H.; SAAD, J. C. C.; OLIVEIRA, S. R. M. Produtividade do feijoeiro sob diferentes potenciais matriciais e fatores de depleção da água no solo. Nativa, Sinop, v. 03, n. 02, p. 109-114, 2015.

CABRAL, C. E. A. Capins Marandu, Decumbens e Convert submetidos à adubação nitrogenada. 2011. 90f. Dissertação (Mestrado em Agricultura Tropical) Faculdade de Agronomia e Medicina Veterinária, Universidade Federal de Mato Grosso, Cuiabá, 2011.

CARARD, M.; NERES, M.A.; TONELLO, C.L. Efeito de doses crescentes de nitrogênio no desenvolvimento de cultivares de Brachiaria brizantha, Revista da FZVA, v.15, n.2, p.135-144, 2008. 
CARDOSO, J.M.S.; ANDRADE, A.C.; MAGALHÃES, J.A.; RODRIGUES, B.H.N; Vieira, J.S.; FOGAÇA, F.H. dos S.; MEHL, H.U.; COSTA, N.L. Fontes e doses de nitrogênio na produtividade do capim Marandu. Revista PUBVET, v. 9, n.8, p.348358, 2015.

DALLACORT, R.; MARTINS, J.A.; INOUE, M.H.; FREITAS, P.S.L.; COLLETI, A.J. Aptidão agroclimática do pinhão manso na região de Tangará da Serra, MT. Revista Ciência Agronômica, v.41, n.3, p.273-379, 2010.

DOURADO, R.L. Características morfogênicas, estruturais e produção de biomassa em capim - Piatã submetido a doses de nitrogênio. 2009. 53f. Dissertação (Mestrado em Ciência Animal) - Faculdade de Agronomia e Medicina Veterinária, Universidade Federal de Mato Grosso, Cuiabá, 2009.

EMERENCIANO NETO, J. V.; PEREIRA, G. F.; DIFANTE, G. S.; OLIVEIRA, L. G. LIMA, A. R.; SANTOS, W. R.; GURGEL, M. F. Produção e estrutura de pastos de capim-massai adubado com dejetos da produção animal. Boletim da Indústria Animal, Nova Odessa, v.73, n.2, p. 111-117, 2016.

FIORI, A.M.R. Altura de corte e adubação potássica de capim-Convert HD 364. 2016. 28f. Trabalho de Conclusão de Curso (Especialização em Zootecnia) Faculdade de Agronomia, Medicina Veterinária e Zootecnia, Universidade Federal de Mato Grosso, Cuiabá, 2016.

FREITAS, R.F.; ROSA, B.; RUGGIERO, J.A.; NASCIMENTO, J.L.; HEINEMAM, A.B.; FERREIRA, P.H.; MACEDO, M. Avaliação do capim Mombaça (Panicum maximum Jacq. submetido a diferentes doses de nitrogênio. Acta Scientiarum Agronomy, v.27, n.1, p. 83-89, 2005.

HOFFMANN, A.; MORAES, E. H. B. K.; MOUSQUER, C. J.; SIMIONI, T. A.; JUNIOR GOMES, F.; FERREIRA, V. B.; SILVA, H. M. Produção de bovinos de corte no sistema de pasto-suplemento no período seco. Nativa, mnv. 02, n. 02, p. 119-130, 2014. Disponível em: . DOI: 10.14583/2318-7670.v02n02a10

IBGE - Instituto Brasileiro de Geografia e Estatística. Pecuária municipal 2016: Centro-Oeste concentra $34,4 \%$ do rebanho bovino do país. 2017. Disponível em: https://agenciadenoticias.ibge.gov.br/agencia-noticias/2013-agencia-denoticias/releases/16992-pecuaria-municipal-2016-centro-oeste-concentra-34-4-dorebanho-bovino-do-pais.html. Acesso em: 10 abr. 2018.

IWAMOTO, B.S.; CECATO, U.; RIBEIRO, O.L.; MARI, G.C.; PELUSO, E.P; LOURENÇO, D.A.L. Características morfogênicas do capim-Tanzânia fertilizado ou não com nitrogênio nas estações do ano. Bioscience Journal, v.31, n.1, p.181-193, 2015.

JACOVETTI, J. Desempenho agronômico e nutricional do capim Mulato II sob doses e fontes de nitrogênio. 2016. 96f. Tese (Doutorado em Produção animal) Escola de Veterinária e Zootecnia, Universidade Federal de Goiás, Goiânia, 2016. 
LEAL, D.M. Produtividade e composição bromatológica da Brachiaria hibrida cv. Mulato II em regime de cortes sob doses de nitrogênio. 2014. 88f. Dissertação (Mestrado em Ciência Animal) - Escola de Veterinária e Zootecnia, Universidade Federal de Goiás, Goiânia, 2014

OLIVEIRA, A.B.B.; ANDRADE, A.C.; MAGALHÃES, J.A.; RODRIGUES, B.H.N; MEHL, H.U.; SANTOS, F.J.S.; SILVA, E.M; COSTA, C.A.A.; COSTA, N.L. Produtividade do capim-Digitária (Digitaria spp.) sob diferentes doses de nitrogênio. PUBVET, v.9, n.2, p.70-75, 2015.

PEDREIRA, B.C. PITTA, R.M.; ANDRADE, C.M.S.; DIAS FILHO, M.B. Degradação de pastagens de Braquiarão (Brachiaria brizantha cv. Marandu) no Estado de Mato Grosso. Sinop: Embrapa Agrossilvipastoril, 2014. 24p.

PORTO, E.M.V. Produção de biomassa de três cultivares do gênero Brachiaria spp. submetidos à adubação nitrogenada. Agropecuária Científica do Semiárido, v.13, n.1, p.9-14, 2017.

SALES, E.C.J.; REIS, S.T.; MONÇÃO, F.P.; ANTUNES, A.B.; ALVES, D.D.A.; AGUILAR, A.C.R.; ANTUNES, A.P.S.; MOTA, V.A.C. Produção de forragem, características estruturais e eficiência de utilização de nitrogênio no capim Marandu. Revista Agrarian, v.7, n.25, p.434-446, 2014.

SILVA FILHO, A.S.; MOUSQUER, C.J; CASTRO, W.J.R.; SIQUEIRA, J.V.M.; OLIVEIRA, V.J.; MACHADO, R.J.T. Desenvolvimento de Brachiaria brizantha cV. Marandu submetido a diferentes doses de ureia. Revista Brasileira de Higiene e Sanidade Animal, v.8, n.1, p.172-188, 2014.

TEIXEIRA, S. O.; TEIXEIRA, E. E. R.; SANTOS, V. B.; YAMASHITA, O. M.; CARVALHO, M. A. C. Produtividade de braquiárias em função da aplicação de fontes e doses de nitrogênio no início da estação seca. In: Seminário de Biodiversidade e Agroecossistemas Amazônicos, 3., 2015, Alta Floresta. Anais... Alta Floresta, 2015. p. 484-489, 2015.

TEODORO, M.S.R. Produção e teor de matéria seca das braquiárias brizanta (Brachiaria brizantha cv. Marandu) e Mulato (Brachiaria hibrida cv. Mulato) nas condições edafoclimáticas do Sudoeste Goiano. 2007. 57f. Trabalho de Conclusão de Curso (Especialização em Zootecnia) - Instituto de Ciências Agrárias, Faculdades Integradas de Mineiros, Mineiros, 2007. 